\title{
Análise da Porosidade Através da Técnica de Microtomografia Computadorizada (Micro-CT) em Amostra Sintética de Rocha
}

\author{
Gleide Alencar do Nascimento Dias, Universidade Federal do Rio de Janeiro.
}

Copyright 2014, SBGf - Sociedade Brasileira de Geofísica

Este texto foi preparado para a apresentação no VI Simpósio Brasileiro de Geofísica, Porto Alegre, 14 a 16 de outubro de 2014. Seu conteúdo foi revisado pelo Comitê Técnico do VI SimBGf, mas não necessariamente representa a opinião da SBGf ou de seus associados. É proibida a reprodução total ou parcial deste material para propósitos comerciais sem prévia autorização da SBGf.

\begin{abstract}
In this study we estimated the porosity of a synthetic rock sample composed of micro glass beads (quartz), with the intention to verify the response of the methodology in a standard model. These were placed in a plastic container and analyzed using the technique of computed microtomography $(\mu \mathrm{CT})$ for transmission of $x$ rays. Measurements were obtained through the equipment SkyScan1173 scanner, which is a $\mu C T$ scanner bench in the sample and x-ray camera are mobile which allows a combination of image with high resolution and acquisition speed. From the data obtained from the scanning was possible to quantify the porosity of the sample in $37.37 \%$ and satisfactorily reconstruct its three-dimensional (3D) model.
\end{abstract}

\section{Resumo}

Nesse trabalho foi estimada a porosidade de uma amostra sintética de rocha composta por micro esferas de vidro (quartzo), com a intenção de verificar a resposta da metodologia em um modelo padrão. Essas foram acondicionadas em um recipiente de plástico e analisadas a partir da técnica de microtomografia computadorizada (micro-CT) por transmissão de raios $\mathrm{x}$. As medidas foram obtidas através do equipamento scanner SkyScan1173, o qual é um micro-tomógrafo de bancada em que a amostra e a câmara de raios $x$ são móveis o que permite uma combinação de imagem com alta resolução e velocidade de aquisição. A partir dos dados obtidos do escaneamento foi possível quantificar a porosidade da amostra em $37,37 \%$ e reconstruir satisfatoriamente o seu modelo tridimensional (3D).

\section{Introdução}

A microtomografia é uma técnica não destrutiva que reconstrói e modela imagem de amostras na escala micrométrica, com resolução e contraste aplicáveis. Tem sido utilizada na indústria do petróleo através da área de petrofísica para medidas diretas de porosidade efetiva, visualização da geometria dos grãos, canais e identificação de minerais. A porosidade é uma propriedade petrofísica das rochas sedimentares, que no caso dos carbonatos tem-se por dificuldade a não seqüência de um padrão, e está relacionada com a capacidade de armazenamento de fluídos, expressando a fração do volume total de uma rocha que pode ser ocupada por fluido. Foi desenvolvida por Godfrey N. Hounsfield em 1972 o que Ihe rendeu o prêmio Nobel de medicina em 1979. Não existe uma distinção clara entre tomografia computadorizada (TC) e micro tomografia computadorizada $(\mu \mathrm{TC})$, porém geralmente usa-se o termo microtomografia para imagens obtidas por tomógrafos que possuem resolução espacial melhor que $100 \mu \mathrm{m}$ (Elliot apud Filho 2012). Os dados da amostra foram obtidos com o scanner SkyScan1173. A partir dos dados obtidos do escaneamento foi possível quantificar a porosidade da amostra, usando o software de tratamento de imagem CT- Analyser, cujo valor encontrado foi de 37,37\%, e construir modelos tridimensionais, que refletem bem a geometria dos grãos das amostras selecionadas

\section{Metodologia}

Os raios $X$ foram descobertos em 8 de novembro de 1895, quando o físico alemão Wilhelm Conrad Roentgen realizava experimentos com os raios catódicos. Raios $X$ podem ser produzidos quando elétrons são acelerados em direção a um alvo metálico. O choque do feixe de elétrons (que saem do catodo com energia de dezenas de $\mathrm{KeV}$ ) com o anodo (alvo) produz dois tipos de raios $X$. Um deles constitui 0 espectro contínuo, e resulta da desaceleração do elétron durante a penetração no anodo. O outro tipo é o raio $X$ característico do material do anodo. Assim, cada espectro de raios $X$ é a superposição de um espectro contínuo e de uma série de linhas espectrais características do anodo.

A microtomografia é uma técnica que utiliza imagens radiográficas em conjunto com algoritmos matemáticos para gerar imagens tridimensionais da estrutura interna do material com resolução espacial que podem chegar à ordem de micrometros. Esta técnica não exige preparação do material e para uma grande quantidade de materiais é uma técnica totalmente não destrutiva. (Perret,1999)

A imagem projetada do raio- $X$ pode corresponder a um modelo de objeto tridimensional (3D). No simples caso, nos podemos descrever isto como uma iluminação de paralelos raios - $X$. No entanto a maioria das fontes de raios $X$ não são capazes de gerar feixes paralelos. $O$ feixe de cone 3D do algoritmo de reconstrução leva em conta a espessura do objecto. Os raios que atravessam parte da frente e parte de trás do objecto não são projectadas sobre a mesma linha do detector, figura 1. 


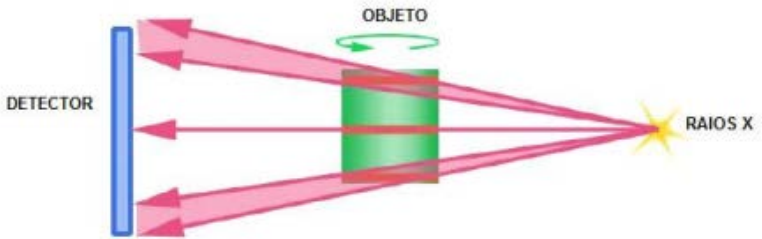

Figure 1 - Geometria do feixe cônico (Skyscan, 2008).

Segundo Chung (2001) um feixe homogêneo de raio $X$ ao passar por uma camada absorvedora tem sua intensidade reduzida exponencialmente dado por

$\phi=\phi_{0} e^{-\mu x}$

$\phi$ é o ângulo do espalhamento final, $\phi_{0}$ é o ângulo do espalhamento inicial, $\mu$ coeficiente de absorção , $x$ espessura de material.

\section{Experimento e Resultados}

O equipamento utilizado no estudo é o SkyScan1173 (figura 3). Este possui um tubo de raios $x$ microfocado com anodo de tungstênio, ponto focal menor que $5 \mu \mathrm{m}$ e potência de $8 \mathrm{~W}$, que pode ser operado com energia variando entre $40 \mathrm{kV}$ e $130 \mathrm{kV}$ e corrente de 0 a $100 \mu \mathrm{A}$. Este microtomógrafo utiliza um detector do tipo "flat panel" com matriz 2240 x 2240 pixels e 12 bits com reconstrução máxima de objetos com $140 \mathrm{~mm}$ de diâmetro e 200 mm de comprimento.

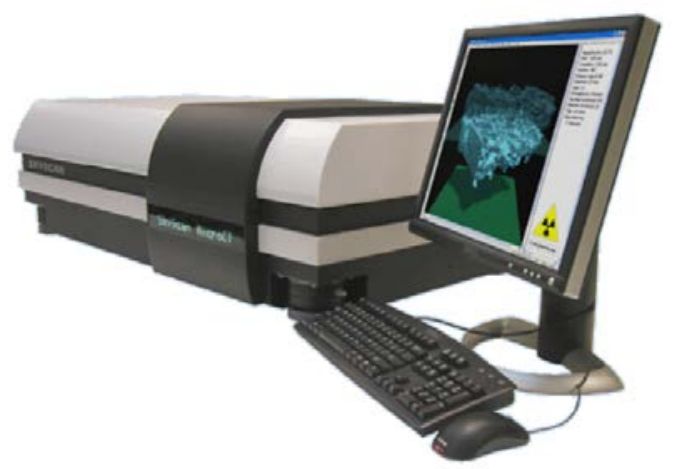

Figura 3 - Ilustração do SkyScan1173, (Skyscan, 2008).

Este sistema utiliza geometria de feixe em forma de leque para aquisição das imagens transmitidas por feixes de raios $x$ do objeto em diferentes posições angulares. Durante a aquisição dos dados o objeto pode rotacionar $180^{\circ}$ ou $360^{\circ} \mathrm{com}$ um passo fixo, a cada passo uma imagem é adquirida sendo salvas como arquivos de 16 bits extensão em TIFF. Após o processo de aquisição, a imagem capturada é reconstruída usando o algoritmo de reconstrução. Quando a reconstrução é terminada, a imagem está pronta para ser analisada e processada.

As imagens foram obtidas operando o microtomógrafo com energia de $90 \mathrm{kV}$, corrente de $86 \mu \mathrm{A}$, filtro de alumínio de $1,0 \mathrm{~mm}$, passo de $0,3^{\circ}$, rotação de $360^{\circ}$ e resolução de 11,98 nm. A figura 2 a seguir resume todas as ações e etapas para gerar os dados das secções transversais.

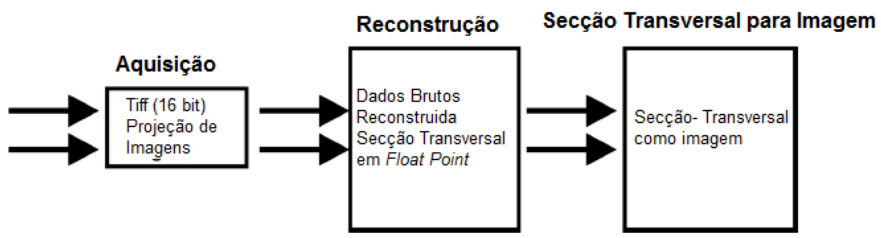

Figura 2 - De aquisição para imagem reconstruída da seção transversal final.

A estimativa de porosidade é feita usando o software de tratamento de imagem CT-Analyser. A imagem reconstruída sofre um tratamento onde é determinada a região de interesse, então é binarizada sendo representada em pixels pretos (sólido, esferas) e brancos (poros). A porosidade é estimada a partir da análise 3D da imagem binarizada. Por se tratar de uma amostra com partículas soltas e não compactadas, a vibração do equipamento interferiu nos resultados, pois essa vibração era transmitida às esferas e alterou levemente o resultado esperado nas imagens. Isso poderia ser atenuado adicionando água e congelando a amostra. Foram usadas micro-esferas de vidro com 0,6 a $0,8 \mathrm{~mm}$ de diâmetro. Como se tratava de uma amostra contendo material inconsolidado foi necessário acondicionar a amostra em recipiente plástico cilíndrico (figura 4).
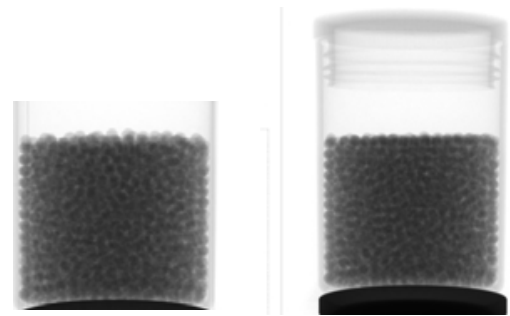

Figura 4 - Microtomografia da amostra.

\section{4 - Resultados e discussões}

Na figura 5 está representada a imagem de uma fatia reconstruída com a correção dos artefatos, abaixo do lado direito é mostrado o gráfico de coeficiente de atenuação. É possível verificar que com aplicado 
correções de endurecimento de feixe e efeito de anel a estrutura representa bem o modelo original.

Para determinar a segmentação das amostras e assim quantificar a porosidade foi utilizado o método de inspeção visual baseado na descrição macroscópica da amostra sendo relevante a geometria dos grãos e o coeficiente de atenuação do raios $X$ para identificação da fase. $O$ valor de porosidade, estimado pela microtomografia, da amostra de esferas de vidro foi de $37,37 \%$

As imagens 2D (bidimensionais) obtidas pelo microtomógrafo (figura 6) e os modelos em 3D da amostra (figura 7). Como mencionado anteriormente, esse valor de porosidade possui um erro relativo à vibração das esferas durante o funcionamento do equipamento, podendo ser minimizado adicionando água à amostra e congelando. Vale lembrar que nesse caso trata-se de um padrão sintético com grãos de excelente seleção.

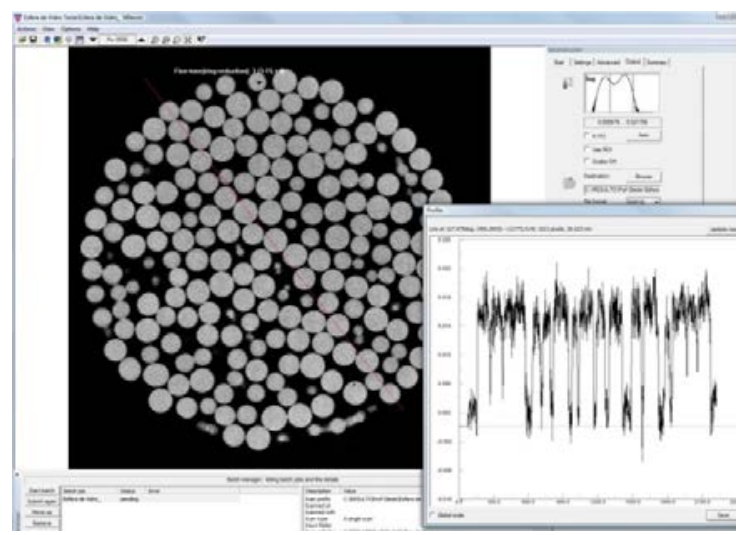

Figura 5 - Correção de anele e endurecimento do feixe. Gráfico de coeficiente de atenuação a direita em baixo.

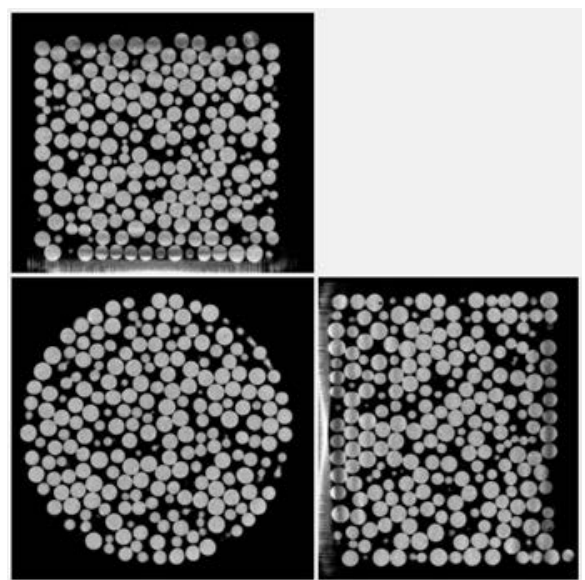

Figura 6 - Microtomografia da amostra.
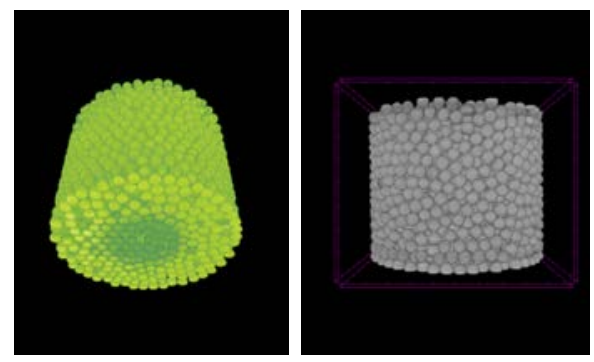

Figura 7 - Modelos 3D.

\section{Discussão e Conclusões}

A técnica de micro-tomografia é uma das técnicas de medições dados petrofísicos que comparada as demais para a obtenção do resultado final leva-se mais tempo durante as fases de aquisição, processamento e interpretação, mas em compensação fornece uma melhor resolução em termos de imagem. As imagens da microtomografia podem serem analisadas de forma 2D e 3D verificando-se a forma do grão, distribuição e conectividades entre eles, preservando as características do plugue de uma rocha. Ë verificado pelos resultados a reconstrução da imagem, que o modelo 3D representou perfeitamente a amostra sintética de rocha com a forma dos grãos esféricos. Concluindo assim efetividade da microtomografia em reconstrução de imagens de materiais inconsolidados.

\section{Agradecimentos}

Ao Professor Leonardo Borhghi (UFRJ) por ter permitido as medidas no micro-CT.

\section{Referências}

Chung, K.C., 2001. Introdução à Física Nuclear, 1 ed. Rio de Janeiro, Editora da Universidade do Estado do Rio de Janeiro.

Filho S. M. 2012. Uso da Técnica da Microtomografia Computadorizada para Análises Não Destrutivas de Formas Farmacêuticas Sólidas e Excipientes. Dissertação do Programa de Pós-Graduação em Ciências Farmacêuticas da Universidade de Sorocaba. Universidade de Sorocaba.

Perret, J., Prasher, S. O., Kantzas, A., Langford, C. 1999. Three Dimensional Quantification of Macropore Network in Undisturbed Soil Cores. Soil society American Journal, v.63, pp. 1530-1543.

Skyscan, 2008. The user's guide, CT- Analyser (version 1.6.6) Disponível em: www. Skyscan.be 